\title{
INSILICO METHOD FOR PREDICTION OF MAXIMUM BINDING AFFINITY AND LIGAND - PROTEIN INTERACTION STUDIES ON ALZHEIMER'S DISEASE
}

\author{
Karthika Perampattu Baskaran 1, Arunagiri Arumugam 2, Ruckmani Kandasamy 1 ,

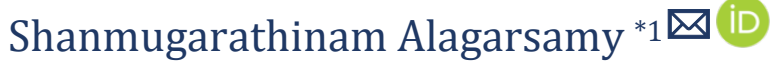 \\ ${ }^{* 1}$ Department of Pharmaceutical Technology, University College of Engineering, Bharathidasan \\ Institute of Technology, Anna University, Tiruchirappalli, India \\ 2 Kirupananda Variyar Engineering College, Vinayaka Mission's Research Foundation (Deemed to \\ be University), Periya Seeragapadi, Salem, India
}

DOI: https://doi.org/10.29121/granthaalayah.v8.i11.2020.2472

Article Type: Research Article

Article Citation: Karthika Perampattu Baskaran, Arunagiri Arumugam, Ruckmani Kandasamy, and Shanmugarathinam Alagarsamy. (2020). INSILICO METHOD FOR PREDICTION OF MAXIMUM BINDING AFFINITY AND LIGAND - PROTEIN INTERACTION STUDIES ON ALZHEIMER'S DISEASE. International Journal of Research -GRANTHAALAYAH, 8(11), 362-370. https://doi.org/10.29121/granthaa layah.v8.i11.2020.2472

Received Date: 15 November 2020

Accepted Date: 30 November 2020

Keywords:

Molecular Docking

Alzheimer's Disease

Acetylcholinesterase

ADME Analysis

Ligand-Protein Interactions

\section{ABSTRACT}

The aim of this study is to perform the molecular docking, identifying the drug likeness, ADME properties of drugs, Ligand-Protein interactions using different software's. Due to the excess activity of Acetylcholinesterase, plaque formation and tau protein aggregation in the brain is the main cause for the Alzheimer's disease. The interaction of Donepezil, Rivastigmine and Chlorzoxazone against Ache protein crystal structure (4EY5, 4EY6, 4EY7) using molecular docking were analyzed. Docking results of Rivastigmine and Chlorzoxazone were compared with Donepezil (widely used drug for Alzheimer's disease) to identify the binding affinity. To verify whether Chlorzoxazone could act similarly as effective drug of Donepezil and also finding in which protein structure, ligands could bind effectively were employed using BIOVIA Discovery Studio software. Among those ligands' interaction with all protein structure, 4EY7 on Rivastigmine $(-7.1 \mathrm{kcal} / \mathrm{mol})$ exhibits maximum binding affinity. The interactions of three ligands were compared with one another, in that Hydrogen bond formation of Chlorzoxazone and Donepezil with 4EY6 and 4EY7 interacting the similar amino acids residues (4EY6ARG165; 4EY7-ASP74) were studied using Insilco studies.

\section{INTRODUCTION}

Alzheimer's disease (AD) is the chronic neurodegenerative disorder (death and malfunctioning of neurons) occurs in the brain. It is characterized by dementia, impairment in memory, complex cognition, language, emotion and behavioral disturbances. The most important causes for this disease is due to the excessive Acetylcholinesterase (AChE) activity, formation of neurotoxic amyloid plaque, and tau protein aggregation. The two pathogenic

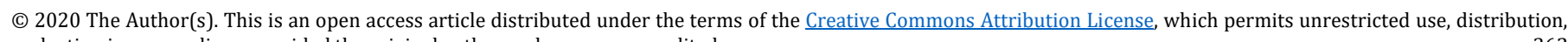
and reproduction in any medium, provided the original author and source are credited. 
characteristics of $A D$ are the neuritic plaques (NPs) of $\beta$-amyloid protein $(A \beta)$ and insoluble twisted fibers called neurofibrillary tangles (NFTs) in the brain. Accumulation of $\beta$-amyloid protein (A $\beta$ ) forms inside the neurons which disturbs neural activity and induces brain tissue damage; Neurofibrillary tangles occur when "Tau" protein (involved in the stabilization of microtubules) aggregation forms in outside of the neurons. Ache is also proposed to play an important role in $\mathrm{A} \beta$-aggregation during plaque formation. Although the pathogenesis of $\mathrm{AD}$ is not fully understood, currently the most efficacious treatment approach for $\mathrm{AD}$ is considered to increase cholinergic neurotransmission in the brain by lowering AChE hydrolysis.

Acetylcholinesterase (AChE) has become a major interest in Alzheimer's disease research. In nervous system, AChE is the efficient enzyme that plays an important role in acetylcholine- mediated neurotransmission. Acetyl cholinesterase is found in many types of conducting tissue: nerve and muscle, central and peripheral tissues, motor and sensory fibers, and cholinergic and noncholinergic fibers. The activity of AChE is higher in motor neurons than in sensory neurons. AChE is a serine hydrolase mainly found at neuromuscular junctions and cholinergic brain synapses. The principal biological role of AChE is rapid hydrolysis of the neurotransmitter ACh to acetate and choline at cholinergic synapses for termination of impulse transmission.

Cholinesterase or AChE inhibitors are majorly used in the treatment of AD to keep ACh levels normal. Cholinesterase inhibitors such as Donepezil, Galantamine, Rivastigmine and Huperzine have been extensively studied as symptomatic treatments for AD. Donepezil is the most favourable Cholinesterase inhibitor, it gives a relatively positive results in $\mathrm{AD}$ treatment.

In this insilico study, Cholinesterase inhibitors such as Donepezil, Rivastigmine and Chlorzoxazone (it exhibits neuroprotection and also has anti-inflammatory effects but its insilico studies in AD has not been investigated), were used for molecular docking. The 3D crystal structure of Protein (Recombinant Human Acetylcholinesterase in Complex with Huperzine (4EY5), Galantamine (4EY6), Donepezil (4EY7) were used to perform docking. The molecular docking was performed using Molecular Graphics Laboratory (MGL Tools) (Autodock 4.0, Autodock Vina) and BIOVIA Discovery Studio). The aim of this study to predict maximum binding affinity and interaction of aminoacids residues by docking different Alzheimer's based ligands (drugs) with Acetylcholinesterase target (protein) [1], [2], [3], [4], [5].

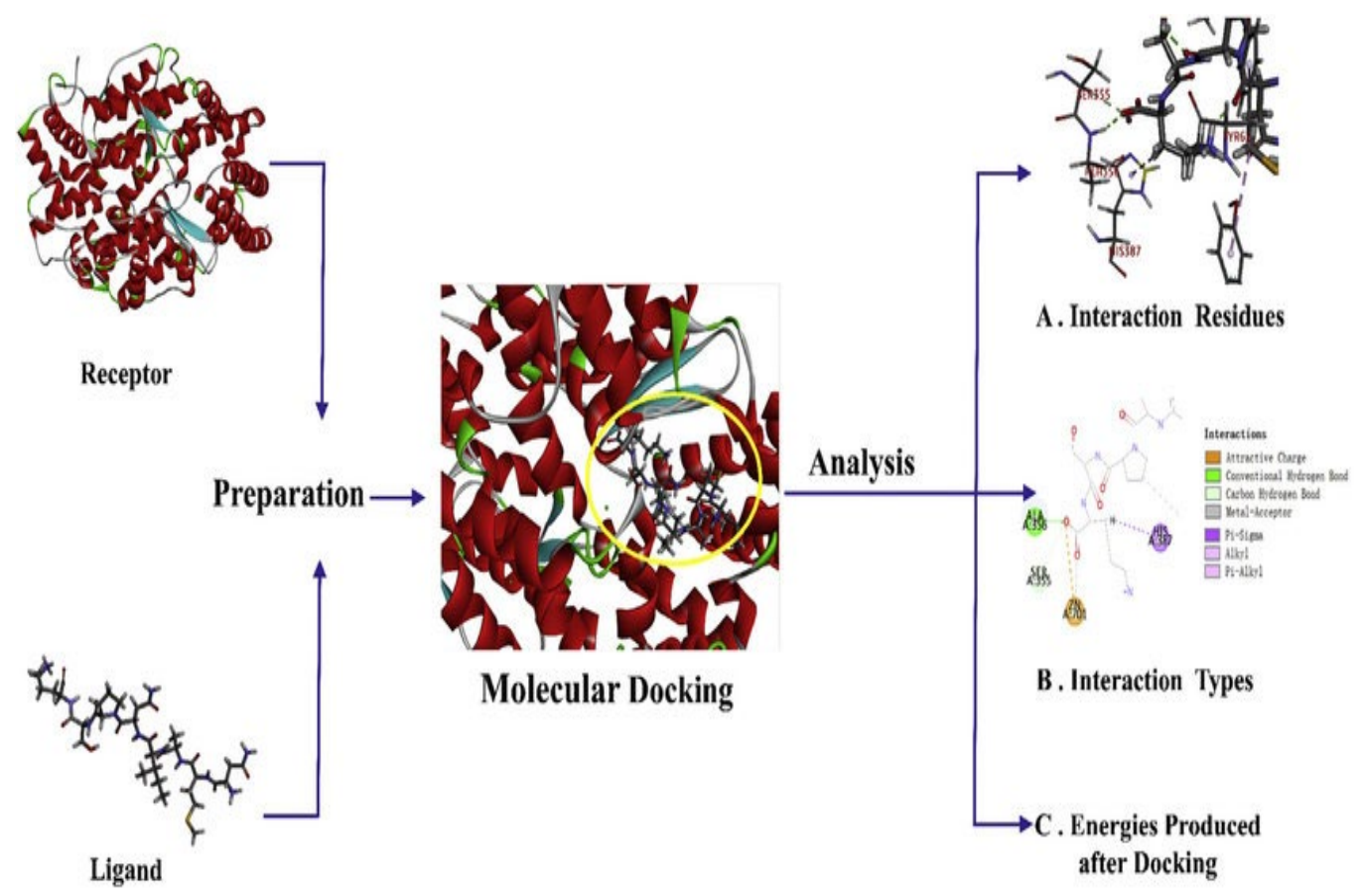

Figure: shown the purpose of Molecular docking. 
Insilico Method for Prediction of Maximum Binding Affinity and Ligand - Protein Interaction Studies on Alzheimer's Disease

\section{METHODOLOGY}

\subsection{PROTEIN PREPARATION}

The three-dimensional structure of protein (Acetylcholinesterase - 4EY5, 4EY6, 4EY7) were retrived from the Protein Data Bank in RCSB (Research Collaboratory For Structural Bioinformatics) site in PDB Format. Prior to molecular docking, protein was prepared by using BIOVIA Discovery Studio software. During preparation polar hydrogens were added and water molecules, hetero atoms were removed from the protein crystal structure for the prevention of unwanted interaction while docking. Among various ligand poses in the protein crystal structure selecting particular ligand pose, then the $\mathrm{X}, \mathrm{Y}$ and $\mathrm{Z}$ attributes were noted in the protein to find the binding affinity [6], [7].

\subsection{LIGAND PREPARATION}

The chemical structure of different drugs (Cholinesterase inhibitors) used for the Alzheimer's disease such as Donepezil, Rivastigmine and Chlorzoxazone were retrived from the Drug bank site in PDB Formats. During preparation, Gasteiger charge were added in the ligands using MGL Tool (Autodock 4). In this software it gives the information about the rotatable bonds for ligands. It also helps for the conversion of protein, ligands structure of the PDB format into the PDBQT (Protein Data Bank, Partial Charge(Q), \& Atom Type (T)) Formats which is essential for finding binding affinity in Autodock Vina [8], [9], [10].

\section{Structure of Donepezil, Rivastigmine, Chlorzoxazone}

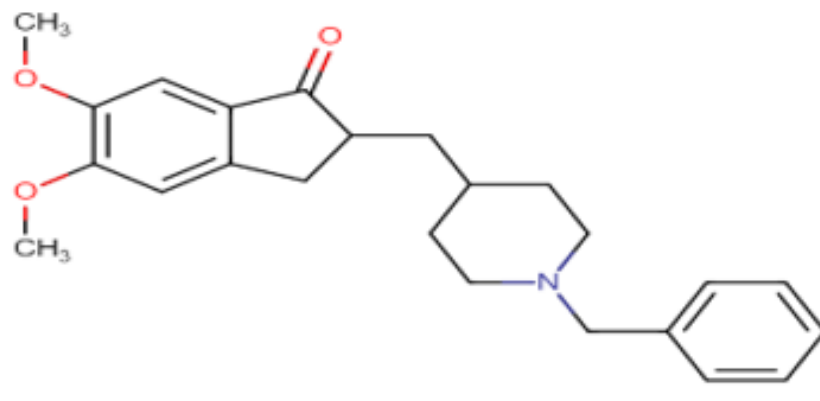

\section{Donepezil}

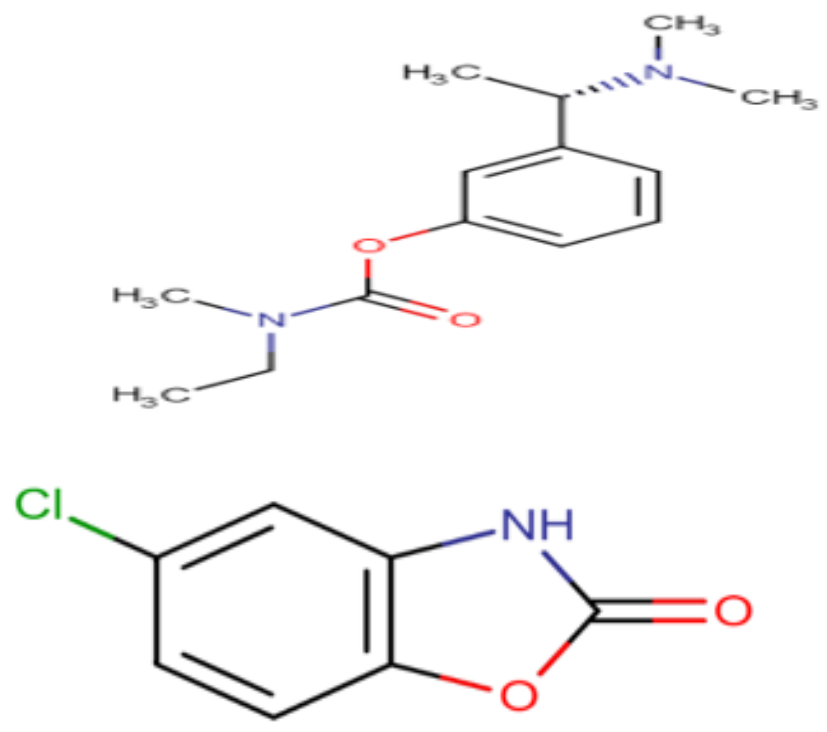

Rivastigmine

Chlorzoxazone 


\subsection{LIGAND BASED ADME PREDICTION}

Swiss ADME is a free web tool which is used to predict the (Absorption, Distribution, Metabolism and Excretion) properties for a chemical structure of the drugs. By using this tool selected ligands will be screened based on the Lipinski's rule of five in order to find the drug likeness. The rules summarize the following physiochemical criteria's

- Molecular weight $<500$

- Number of hydrogen bond acceptors $\leq 10$

- Number of hydrogen bond donors $\leq 5$

- Molecules should have $\log \mathrm{P} \leq 5$

There is a problem in the bioavailability of drugs if molecules will violate more than one of these rules [11], [12], [13], [14], [15].

\subsection{MOLECULAR DOCKING}

Molecular docking was performed to predict the maximum binding affinity between the ligands (inhibitors) and the protein crystal structures using Autodock vina and for finding the type of aminoacids residues interaction with the ligand using BIOVIA Discovery Studio software. Three inhibitors of AChE (Donepezil, Rivastigmine and Chlorzoxazone) were docked with AChE receptors (4EY5, 4EY6, 4EY7). For Autodock vina, empirical scoring functions helps to calculate the binding affinity using Grid parameters (X,Y and Z attributes) [16], [17], [18], [19], [20]. Various types of interactions occur such as Hydrogen bond, Electrostatic, Hydrophobic, Vander waals force interactions between the Ligand-Protein. Based on the number of hydrogen bond (bioactive region) interaction between ligand-protein, particular ligand mode was selected. The best docking score is considered as $(<$ than -10$)$. For hydrophobic interactions between -8 to -9 the docking score is good. Lower the binding energy, higher the binding affinity occurs between the ligand-protein [21], [22], [23], [24], [25], [26].

\section{RESULTS AND DISCUSSION}

\subsection{VALIDATION OF BIOVIA DISCOVERY STUDIO AND AUTODOCK VINA}

To validate the BIOVIA Discovery Studio software, re-docking the 3D crystal structure of Protein (Recombinant Human Acetylcholinesterase in Complex with Huperzine (4EY5), Galantamine (4EY6), Donepezil (4EY7) using Cholinesterase inhibitors as Donepezil (standard drug), Rivastigmine, Chlorzoxazone. Among three different protein structures, 4EY7 with these three inhibitors shows highest binding affinity (docking score) using Autodock Vina software. shown in (Table 1). Aminoacids residue of 4EY7 with three inhibitors, Chlorzoxazone - aminoacid residue relates to standard drug Donepezil - aminoacid residue interactions were similar. (Figure 1).

\subsection{INSILICO MOLECULAR DOCKING ANALYSIS}

Molecular docking analysis is used for the prediction of the strength of the interactions between the ligandsprotein structure. The binding mode of three different protein crystal structures with the three ligands was investigated by doing insilico analysis, glide docking. The results of maximum binding affinity were described in (Table 1), and the type of aminoacids residue interactions with the ligands were showed in (Figure 1). Among all ligands, Rivastigmine showed highest docking score comparing with Chlorzoxazone. Also, the similar aminoacids interactions occurs for Chlorzoxazone when comparing with the standard drug of Donepezil.

ADME analysis for all the ligands shown in (Table 2), It shows the physicochemical properties, drug-likeness and also shows the brain penetration for the particular ligand molecule using SwissADME online free web tool, and to evaluate the bioactivity score for particular ligand using Molinspiration free online web tool. Ligand which obeys the Lipinski's rule of five to be considered as drug like potential. 
Insilico Method for Prediction of Maximum Binding Affinity and Ligand - Protein Interaction Studies on Alzheimer's Disease

Table 1: Docking scores and the Hydrogen bond formation results obtained between the interactions of ligands (Donepezil, Rivastigmine, Chlorzoxazone) and Protein crystal structure - AchE (4EY5, 4EY6, 4EY7).

\begin{tabular}{|c|c|c|c|c|c|c|}
\hline \multirow{2}{*}{ LIGANDS } & \multicolumn{2}{|c|}{ 4EY5 } & \multicolumn{2}{c|}{ 4EY6 } & \multicolumn{2}{c|}{ 4EY7 } \\
\cline { 2 - 7 } & $\begin{array}{c}\text { Binding } \\
\text { affinity } \\
\text { (kcal/mol) }\end{array}$ & $\begin{array}{c}\text { H-bond } \\
\text { formation }\end{array}$ & $\begin{array}{c}\text { Binding } \\
\text { affinity } \\
\text { (kcal/mol) }\end{array}$ & $\begin{array}{c}\text { H-bond } \\
\text { formation }\end{array}$ & $\begin{array}{c}\text { Binding } \\
\text { affinity } \\
\text { (kcal/mol) }\end{array}$ & $\begin{array}{c}\text { H-bond } \\
\text { formation }\end{array}$ \\
\hline $\begin{array}{c}\text { Donepezil } \\
\text { (standard) }\end{array}$ & -7.2 & TYR72 & -5.1 & $\begin{array}{c}\text { ARG165 } \\
\text { GLY163 }\end{array}$ & -9.8 & $\begin{array}{c}\text { TYR341 } \\
\text { ASP74 }\end{array}$ \\
\hline Rivastigmine & -6.3 & PHE295 & -3.3 & MET241 & -7.1 & PHE295 \\
GRG296
\end{tabular}

Table 2: ADME (Physicochemical properties, drug-likeness and the bioactivity score of ligands.

\begin{tabular}{|c|c|c|c|c|c|}
\hline $\begin{array}{c}\text { Name of } \\
\text { ligands }\end{array}$ & $\begin{array}{c}\text { Molecular weight } \\
(\mathrm{g} / \mathrm{mol})\end{array}$ & $\begin{array}{c}\text { H-bond } \\
\text { acceptor }\end{array}$ & $\begin{array}{c}\text { H-bond } \\
\text { donor }\end{array}$ & $\begin{array}{c}\text { Log } \\
\mathrm{P}\end{array}$ & $\begin{array}{c}\text { Bioactivity score (Enzyme } \\
\text { inhibitor) }\end{array}$ \\
\hline Donepezil & 379.49 & 4 & 0 & 3.92 & 0.25 \\
\hline Rivastigmine & 236.31 & 3 & 0 & 2.99 & -0.06 \\
\hline Chlorzoxazone & 169.57 & 2 & 1 & 1.54 & -0.52 \\
\hline
\end{tabular}

Thus, every ligand obeys the Lipinski's rule of five using SwissADME and Molinspiration online web tool.

\section{Lipinski's Rule}

- Molecular weight (acceptable range: $<500$

- Hydrogen bond acceptor (acceptable range: $\leq 10$ )

- Hydrogen bond donor (acceptable range: $\leq 5$ )

- High lipophilicity - expressed as LogP

- (acceptable range: $\leq 5$ ).

A.

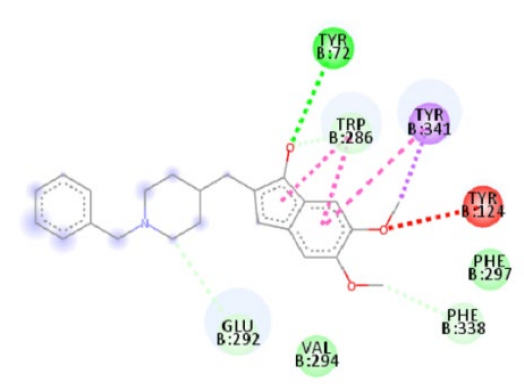

A.

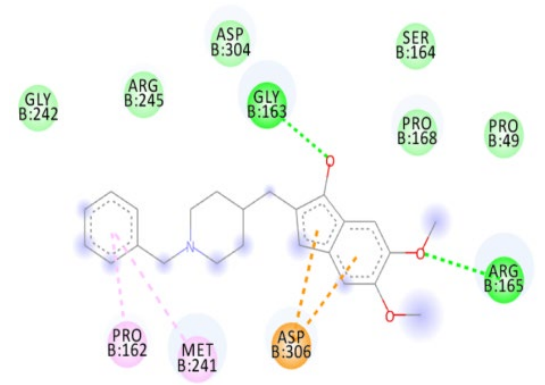

4EY5

B.

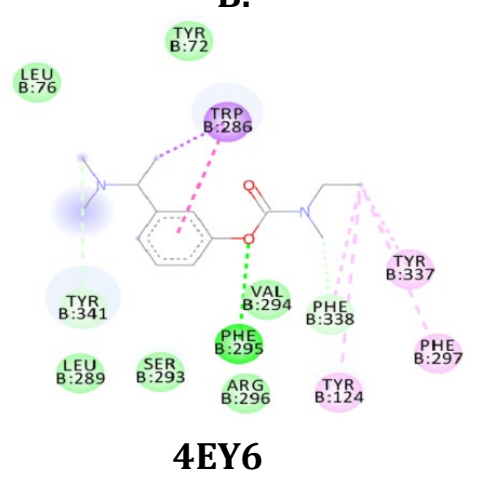

B.

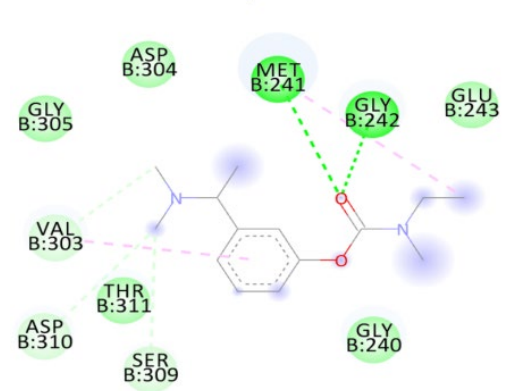

C.

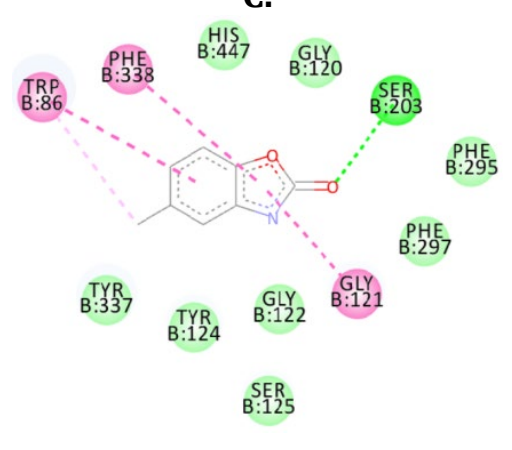

C.

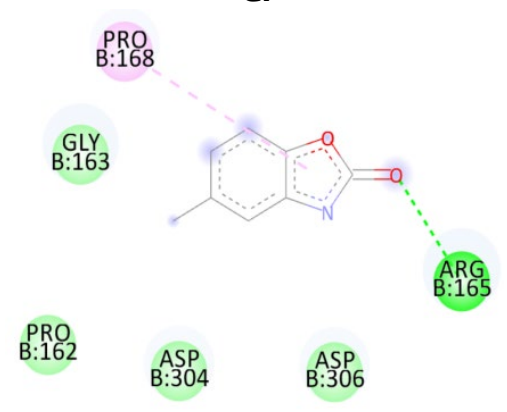


A.

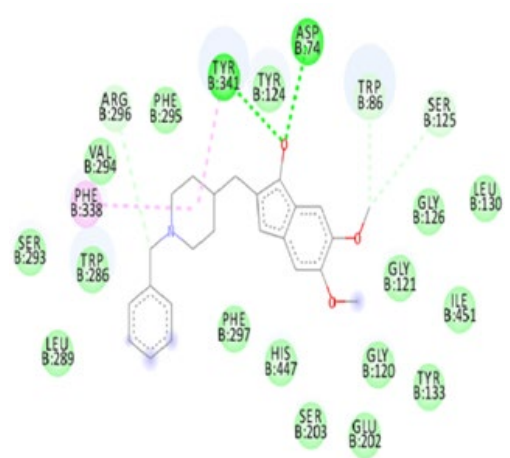

4EY7

B.

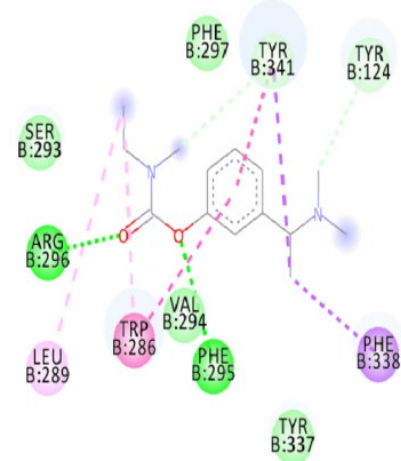

C.

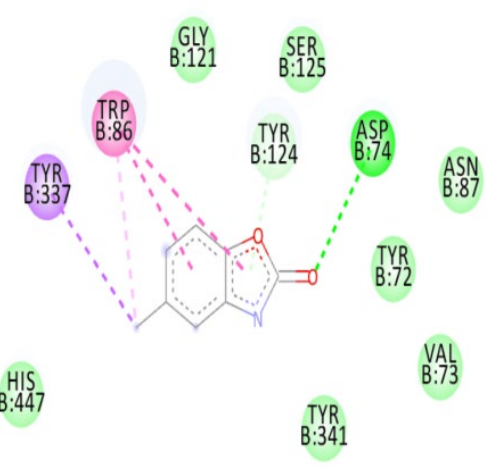

Figure 1: Amino Acids residue (4EY5, 4EY6, 4EY7) 2d-interaction with the ligands (A. Donepezil, B. Rivastigmine, C. Chlorzoxazone).

Green colour indicate the hydrogen bond interaction between the aminoacid residues and ligand.

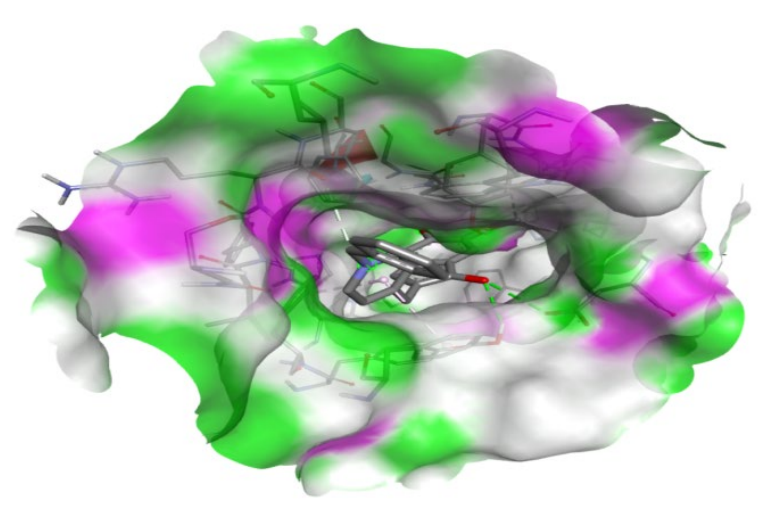

Donepezil

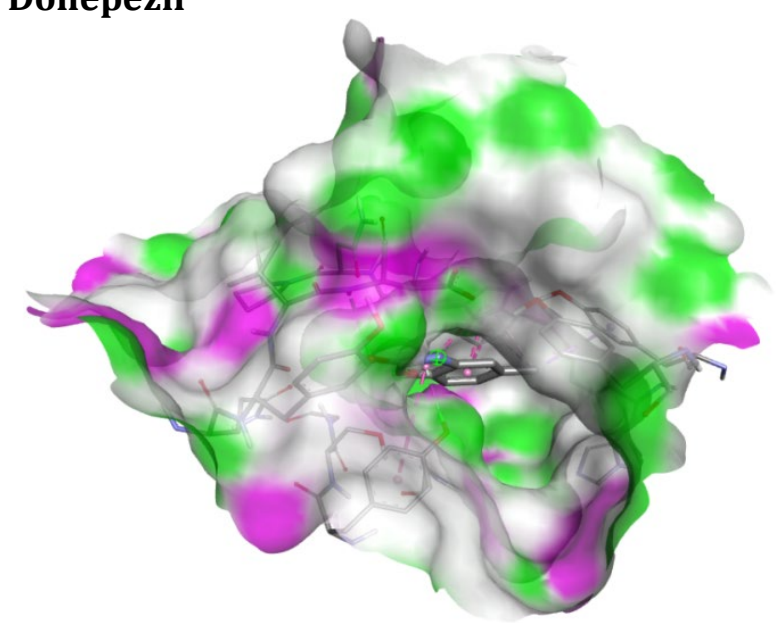

Chlorzoxazone

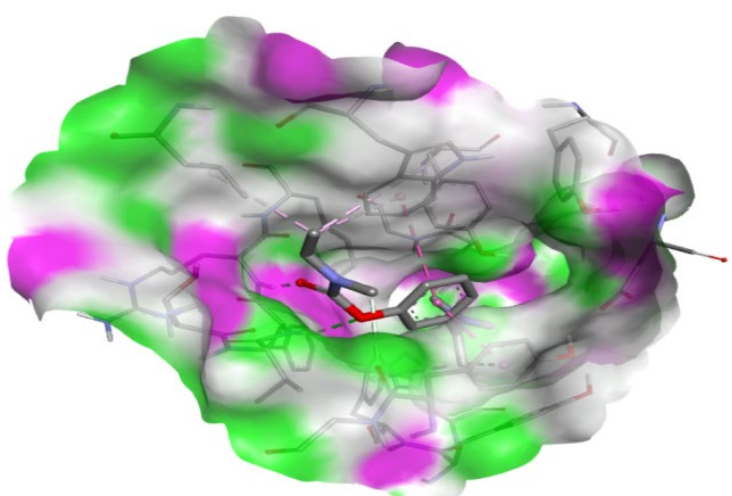

Rivastigmine

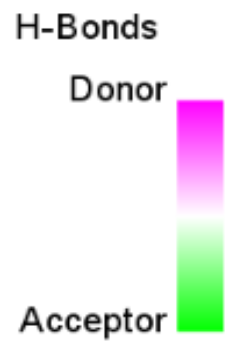

Figure 2: LIGANDS COVERED BY THE RECEPTOR [4EY7] SURFACE

\section{CONCLUSION}

From these insilico study, molecular docking has been performed for Rivastigmine and Chlorzoxazone using standard drug as Donepezil. This study results demonstrate that all three ligands docked well with the active site of AChE protein crysal structure of 4EY6 and 4EY7, but for 4EY5 there are more hydrophobic interactions occur with 
Insilico Method for Prediction of Maximum Binding Affinity and Ligand - Protein Interaction Studies on Alzheimer's Disease

the ligands. The interactions of three ligands were compared with one another, in that Hydrogen bond formation of Chlorzoxazone and Donepezil with 4EY6 and 4EY7 interacting the similar aminoacids residues (4EY6-ARG165; 4EY7-ASP74). Among three protein structures, 4EY7 with the ligand interactions gives the maximum binding affinity. Chlorzoxazone were capable of binding inside the AChE (4EY5, 4EY6 and 4EY7 active site). Thus, insilico studies for Chlorzoxazone in Alzheimer's disease has been investigated and also Chlorzoxazone could be an effective for the treatment of Alzheimer's disease.

\section{SOURCES OF FUNDING}

This research received no specific grant from any funding agency in the public, commercial, or not-for-profit sectors.

\section{CONFLICT OF INTEREST}

The author have declared that no competing interests exist.

\section{ACKNOWLEDGMENT}

The authors gratefully acknowledge the support received from Department of Science and Technology, GoI, New Delhi National Facility for Drug Development (NFDD) for Academia, Pharmaceutical and Allied Industries.

\section{REFERENCES}

[1] Sheikh Arslan sehgal, Mirza A.Hammad, Rana Adnan Tahir, Hafiza Nisha Akram and Faheem Ahmad - Current therapeutics molecules and targets in Neurodegenerative disease based on In-silico drug design. 2018, 16, 649-663.

[2] Kaliappan Ganesan - (Docking study of Benzothiazole - Piperazines: Ache Inhibitors for Alzheimer disease. 2017, 19, Pages: 103-107.

[3] Shivani kumar, Suman Chowdhury and Suresh kumar. In-silico repurposing of antipsychotic drugs for Alzheimer disease. 2017, 18;76.

[4] Chaudhary A, Maurya PK, Yadav BS, Singh S, Mani A. Current therapeutic Targets for Alzheimer's Disease. 2018, 3:74-84.

[5] Martyn JAJ, Fagerlund MJ, Eriksson LI, Basic principles of neuromuscular transmission, Anaesthesia, 64, 2009, $1-9$.

[6] Cheung J, Rudolph MJ, Burshteyn F, Cassidy MS, Gary MS, Love J, Franklin MC, Height JJ, Structures of human acetylcholinesterase in complex with pharmacologically important ligands, J. Med. Chem., 55, 2012, 1028210286.

[7] Dvir H, Silman I, Harel M, Rosenberry TL, Sussman JL, Acetylcholinesterase: From 3D Structure to Function, Chem. Biol. Interact., 187, 2010, 10-22.

[8] Colovic MB, Krstic DZ, Lazarevic- Pasti TD, Bondzic AM, Vasic VM, Acetylcholinesterase Inhibitors: Pharmacology and Toxicology, Current Neuropharmacology, 11, 2013, 315-335.

[9] Li JK, Zhang J, Rodrigues MC, Ding DJ, Longo JPF, Azevedo RB, Muehlmann LA, Jiang CS, Synthesis and evaluation of novel 1,2,3- triazole-based acetylcholinesterase inhibitors with neuroprotective activity, Bioorganic \& Medicinal Chemistry Letters, 26, 2016, 3881- 3885.

[10] Quinn DM, Acetylcholinesterase: enzyme structure, reaction dynamics, and virtual transition states, Chem. Rev., 87, 1987, 955- 975.

[11] Lipinski A, Lombardo F, Dominy BW, Feeney PJ (1997) Experimental and computational ap-proaches to estimate solubility and permeability in drug discovery and development settings. Adv Drug Del Rev 23: 3-25.

[12] Ballard CG, Advances in the treatment of Alzheimer's disease: benefits of dual cholinesterase inhibition, Eur. Neurol., 47, 2002, 64-70. 
[13] Mehta M, Adem A, Sabbagh M, New Acetylcholinesterase inhibitors for alzheimer's disease, Int. J. Alzheimers. Dis., 2012, 728983.

[14] Munoz-Torrero D, Acetylcholinesterase inhibitors as disease modifying therapies for alzheimer's disease, Curr. Med. Chem., 15, 2008, 2433-2455.

[15] Jain AN, Scoring functions for protein-ligand docking, Curr. Protein Pept. Sci., 7, 2006, 407-420.

[16] Dickerson TJ, Beuscher AE IV, Rogers CJ, Hixon MS, Yamamoto N, Xu Y, Olson AJ, Janda KD. Discovery of Acetylcholinesterase peripheral anionic site ligands through computational refinement of a directed library. Biochemistry. 2005; 44(45):14845-53.

[17] Hung-Jin Huang, Cheng-Chun Lee and Calvin Yu-Chian Chen. Insilico design of BACE1 inhibitor for Alzheimer disease by Traditional Chinese Medicine. 2014; 741703.

[18] Hardy J, Selkoe DJ (2002) Medicine - the amyloid hypothesis of alzheimer's disease: Progress and problems on the road to therapeutics. Science 297: 353- 356.

[19] Aguzzi A, O'Connor T (2010) Protein aggregation diseases: pathogenicity and therapeutic per-spectives. Nat Rev Dru 9: 237-248.

[20] Hawkes CA, Ng V, MacLaurin J (2009) Small molecule inhibitors of alpha-beta aggregation and neurotoxicity. Drug Dev Res 70: 111-124.

[21] Lahiri DK, Farlow MR, Sambamurti K, Greig NH, Giacobini E, Schneider LS (2003) A critical analysis of new molecular targets and strategies for drug developments in Alzheimer's disease. Current drug targets 4: 97112.

[22] Cheung J, Rudolph MJ, Burshteyn F, Cassidy MS, Gary EN, Love J, et al. (2012) Structures of human acetylcholinesterase in complex with pharmacologically important ligands. Journal of medicinal chemistry 55: 10282-10286.

[23] Auriacombe S., J.J. Pere, Y. Loria-Kanza, B. Vellas, Efficacy and safety of rivastigmine in patients with Alzheimer's disease who failed to benefit from treatment with donepenzil, Curr. Med. Res. Opin. 18 (3) (2002) 129-138.

[24] McGleenon B.M., K.B. Dynan, A.P. Passmore, Acetylcholinesterase inhibitors in Alzheimer's disease, Br. J. Clin. Pharmacol. 48 (4) (1999) 471-480.

[25] Kryger G., I. Silman, J.L. Sussman, Structure of acetylcholinesterase complexed with E2020 (Aricept): implications for the design for the new anti-Alzheimer drugs, Structure 7 (1999) 297-307.

[26] Mohamed T., P.P.N. Rao, Alzheimer's disease: emerging trends in small molecule therapies, Curr. Med. Chem. 18 (28) (2011) 4299-4320. 